EPJ Web of Conferences 106, 03001 (2016)

DOI: $10.1051 /$ epjconf/201610603001

(C) Owned by the authors, published by EDP Sciences, 2016

\title{
Comparison of Analysis Results Between 2D/1D Synthesis and RAPTOR-M3G in the Korea Standard Nuclear Plant (KSNP)
}

\author{
Mi Joung Lim ${ }^{1, a}$, Young Jae Maeng ${ }^{1}$, Arnold H. Fero ${ }^{2}$, and Stanwood L. Anderson ${ }^{2}$ \\ ${ }^{1}$ Korea Reactor Integrity Surveillance Technology, 168 Gajeong- ro, Yuseong-gu Daejeon, Korea \\ ${ }^{2}$ Westinghouse Electric Company LLC, 1000 Westinghouse Drive, Cranberry Township, Pennsylvania \\ 16066-5228, USA
}

\begin{abstract}
The 2D/1D synthesis methodology has been used to calculate the fast neutron $(\mathrm{E}>1.0 \mathrm{MeV})$ exposure to the beltline region of the reactor pressure vessel. This method uses the DORT 3.1 discrete ordinates code and the BUGLE-96 cross-section library based on ENDF/B-VI. RAPTOR-M3G (RApid Parallel Transport Of Radiation-Multiple 3D Geometries) which performs full 3D calculations was developed and is based on domain decomposition algorithms, where the spatial and angular domains are allocated and processed on multi-processor computer architecture. As compared to traditional singleprocessor applications, this approach reduces the computational load as well as the memory requirement per processor. Both methods are applied to surveillance test results for the Korea Standard Nuclear Plant (KSNP)-OPR (Optimized Power Reactor) 1000 MW. The objective of this paper is to compare the results of the KSNP surveillance program between 2D/1D synthesis and RAPTOR-M3G. Each operating KSNP has a reactor vessel surveillance program consisting of six surveillance capsules located between the core and the reactor vessel in the downcomer region near the reactor vessel wall. In addition to the InVessel surveillance program, an Ex-Vessel Neutron Dosimetry (EVND) program has been implemented. In order to estimate surveillance test results, cycle-specific forward transport calculations were performed by 2D/1D synthesis and by RAPTOR-M3G. The ratio between measured and calculated $(\mathrm{M} / \mathrm{C})$ reaction rates will be discussed. The current plan is to install an EVND system in all of the Korea PWRs including the new reactor type, APR (Advanced Power Reactor) 1400 MW. This work will play an important role in establishing a KSNP-specific database of surveillance test results and will employ RAPTOR-M3G for surveillance dosimetry location as well as positions in the KSNP reactor vessel.
\end{abstract}

\section{Introduction}

This paper presents comparisons of analysis results between 2D/1D synthesis and RAPTOR-M3G in the Korea Standard Nuclear Plant (KSNP). The KSNP is similar to the Combustion Engineering (CE) design plants where the reactor was supplied by CE and DOOSAN. Each of these operating reactors

\footnotetext{
${ }^{a}$ Corresponding author: mjlim@krist.co.kr
}

This is an Open Access article distributed under the terms of the Creative Commons Attribution License 2.0, which permits unrestricted use, distribution, and reproduction in any medium, provided the original work is properly cited. 
has a reactor vessel surveillance program consisting of six surveillance capsules located between the barrel and the reactor vessel in the downcomer region near the reactor vessel inner-wall (In-Vessel). A comprehensive Ex-Vessel Neutron Dosimetry program is also implemented in all KSNP (OPR1000). The six surveillance capsules are located at the following azimuthal angels: $83^{\circ}, 97^{\circ}, 104^{\circ}$, $263^{\circ}, 277^{\circ}$, and $284^{\circ}$. Those six positions correspond to first-octant-equivalent angles of $7^{\circ}$ and $14^{\circ}$. Ex-Vessel Neutron Dosimetry capsules located at angles of $0^{\circ}, 7^{\circ}, 14^{\circ}$, and $45^{\circ}$. The reasons for that positioning are to locate dosimetry at angles that correspond to the angles of the surveillance capsules (7 and 14 degrees).

To analyze In-Vessel and Ex-Vessel surveillance programs, traditional two dimensional (2D) and 1D synthesis methodologies have been widely applied to evaluate the fast neutron $(\mathrm{E}>1.0 \mathrm{MeV})$ fluence exposure to the reactor vessel. Full 3D calculations using RAPTOR-M3G are critical for KSNP EVND evaluation due to the complexity of the cavity which is ex-core detector resin canister and RPV support column.

\section{Background}

The Code of Federal Regulations (CFRs), Title 10, Part 50, Appendix H [1], requires that neutron dosimetry be present to monitor the reactor vessel throughout plant life and that material specimens be used to measure damage associated with the end-of-life fast neutron exposure of the reactor vessel. Currently, Ex-Vessel Neutron Dosimetry (EVND) sets are installed in 16 operating pressurized water reactors (PWRs) in Korea. Among the 16 PWRs, Hanbit (HB) Units 3, 4, 5, \& 6 and Hanul (HU) Units 3, 4, 5, \& 6 are Korea Standard Nuclear Plants (KSNPs). The EVND Program has been designed primarily to meet the code and to provide a long term monitoring of fast neutron exposure distributions within the reactor vessel wall that could experience significant radiation induced increases in reference nil ductility transition temperature $\left(\mathrm{RT}_{\mathrm{NDT}}\right)$ over the service lifetime of the plant.

\section{Transport Calculation Method Discussion}

Traditional 2D and 1D Synthesis method uses 2D and 1D transport solutions in order to obtain 3D neutron flux distribution (Eq. (1)) as described in US Regulatory Guide 1.190 [2] :

$$
\phi(r, \theta, z)=\phi(r, \theta) \bullet \frac{\phi(r, z)}{\phi(r)} .
$$

Where, $\phi(r, \theta, z)$ is the synthesized 3D neutron flux distribution, $\phi(r, \theta)$ is the 2D transport solution in $\mathrm{r}, \theta$ geometry, $\phi(r, z)$ is the 2D solution for a cylindrical reactor model using the actual axial core power distribution, and $\phi(r)$ is the 1D solution for a cylindrical reactor model using the same source per unit height as that used in the $r, \theta$ 2D calculation.

RAPTOR-M3G (RApid Parallel Transport $\underline{\text { Of }}$ Radiation - Multiple $\underline{3 D}$ Geometries) is a parallel, deterministic radiation transport code developed by Westinghouse.

The plant-specific 2D/1D and 3D geometric models are shown in Figs. 1, 2, and 3.

\section{Comparisons of Calculation and Measurement Results}

The neutron dosimetry capsule sensor reactions combined provide a means to measure the fast neutron energy spectrum inside the reactor structures and in the reactor cavity. The measurements were done by gamma-ray spectrometry using high resolution HPGe detectors. The measured specific activities of these reactions are converted to the reaction rates and then compared to the calculated. In addition to the six Ex-Vessel Neutron Dosimetry capsules that have been withdrawn for this analysis, the previously 

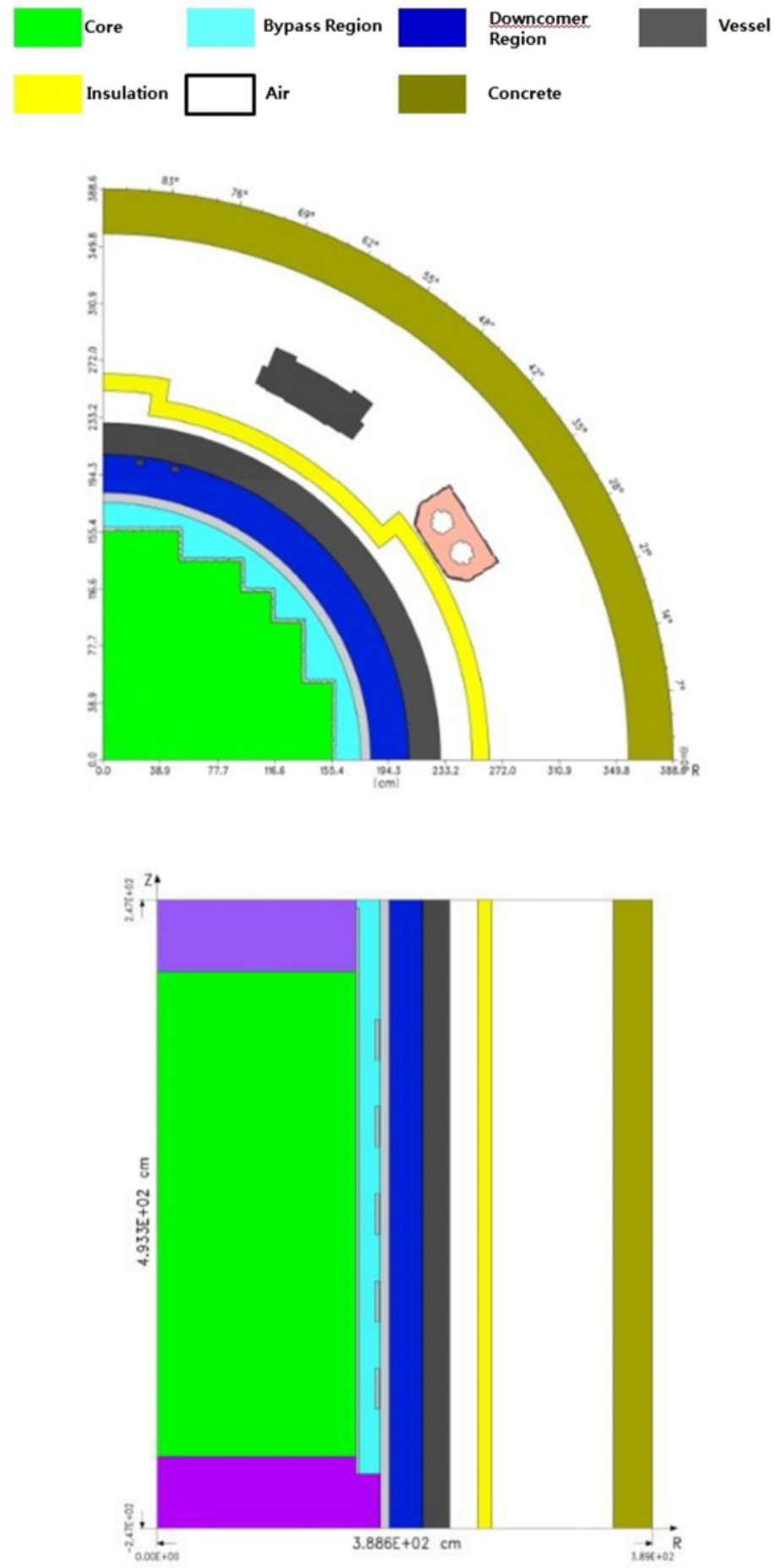

Figure 1. Core Midplane Geometry R- $\theta$ and Axial Geometry R-Z of 2D/1D Synthesis model. 
EPJ Web of Conferences
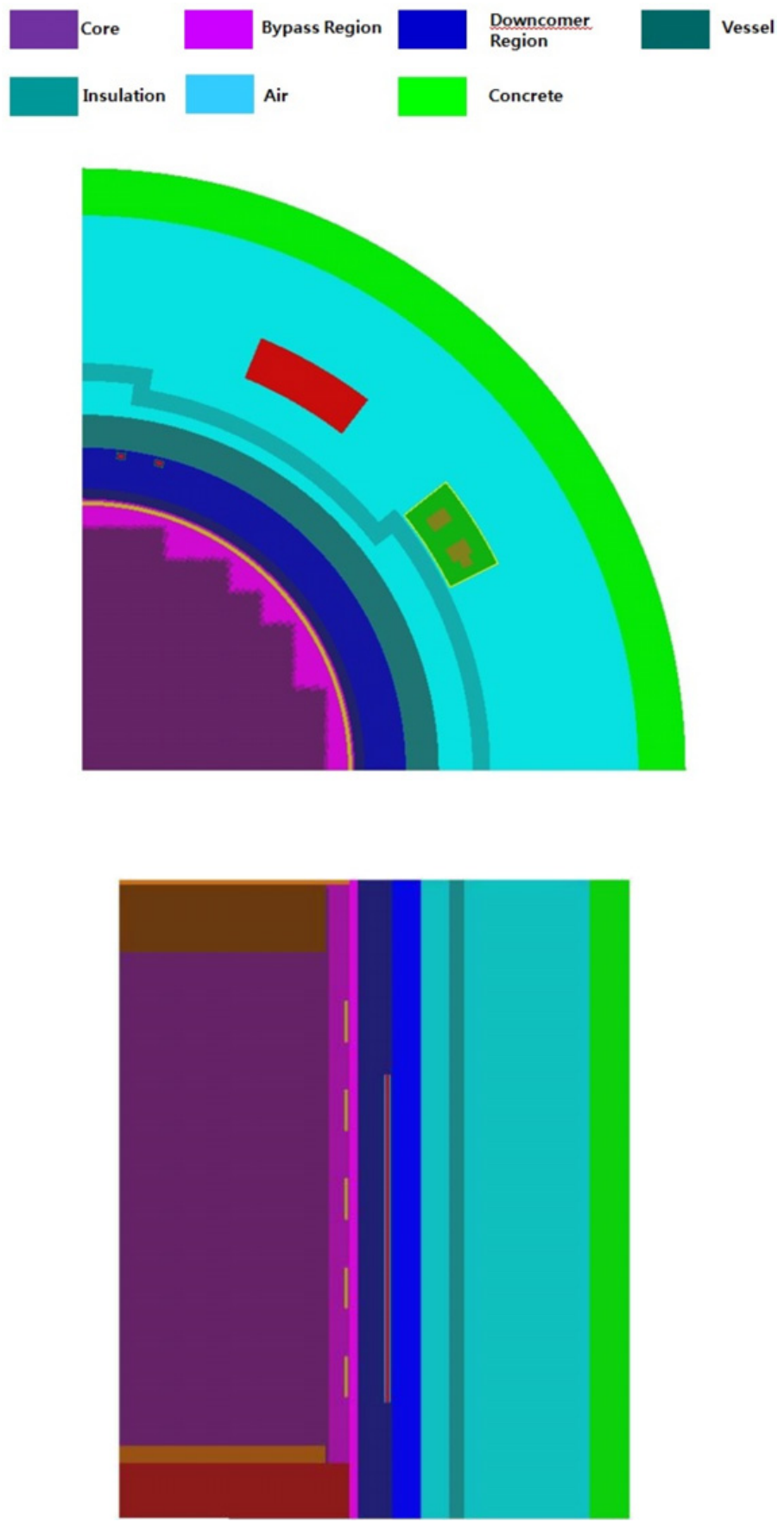

Figure 2. Core Midplane Geometry R- $\theta$ and Axial Geometry R-Z of RAPTOR-M3G model. 

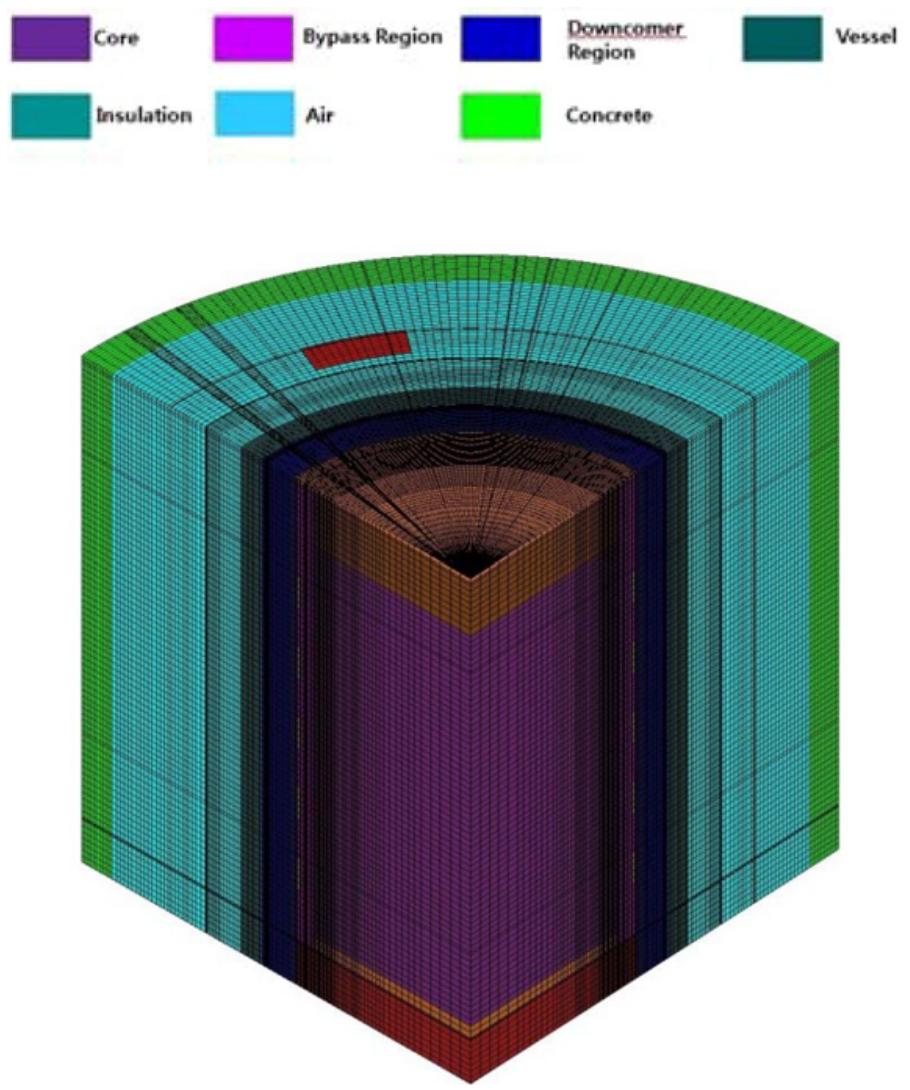

Figure 3. Geometry and Mesh of RAPTOR-M3G model.

withdrawn in-vessel surveillance capsule dosimetry sensors have been re-analyzed using in order to provide more measurement data points to validate the transport calculation model.

The dosimetry calculations were performed with the RadTrack ${ }^{\mathrm{TM}}$ [3] Code System. A plantand cycle-specific library of flux data is constructed within RadTrack using radial and axial power distributions, fuel design specifications, system pressure and temperatures.

Comparisons of the measurement results from each of previously withdrawn in-vessel and six ex-vessel sensor set irradiations with corresponding analytical predictions were used to demonstrate compliance with the requirements of Regulatory Guide 1.190. The total database summary of the measurement-to-calculation (M/C) comparisons based on the individual sensor reactions with the leastsquares adjustment procedure [4] are summarized in Tables 1 to 4 for reactions sensitive in the fast energy range. Uncertainty was calculated by the standard deviation in the average.

These 2D-Calculation data comparisons show similar and consistent results with the linear average $\mathrm{M} / \mathrm{C}$ ratio of 0.94 to 1.09 for in-vessel and 0.96 to 1.10 for ex-vessel in good agreement. The comparisons demonstrate that the $\pm 20 \%$ ( $1 \sigma$ ) for in-vessel and $\pm 30 \%$ for ex-vessel agreement between calculation and measurement required by Regulatory Guide 1.190 .

These 3D-Calculation data comparisons show similar and consistent results with the linear average $\mathrm{M} / \mathrm{C}$ ratio of 0.97 to 1.08 for in-vessel and 0.96 to 1.07 for ex-vessel in good agreement. The comparisons demonstrate that the $\pm 20 \%$ ( $1 \sigma)$ for in-vessel and $\pm 30 \%$ for ex-vessel agreement between calculation and measurement required by Regulatory Guide 1.190 . 
Table 1. Summary of Measurement to 2D-Calculation for In-Vessel of KSNP.

\begin{tabular}{|c|c|c|c|c|c|c|c|c|}
\hline Reaction & HB3 $^{*}$ & HB4* & HB5 & HB6 & HU3 & HU4 & HU5 & HU6 \\
\hline${ }^{{ }^{63} \mathbf{C u}(\mathbf{n}, \alpha)^{\mathbf{6 0}} \mathbf{C o}}$ & 1.07 & 1.10 & 1.03 & 1.06 & 1.16 & 1.05 & 1.13 & - \\
\hline${ }^{46} \mathbf{T i}(\mathbf{n}, \mathbf{p})^{\mathbf{4 6}} \mathbf{S c}$ & 1.09 & 1.03 & 0.97 & 1.02 & 1.10 & 1.00 & 1.08 & 1.17 \\
\hline${ }^{54} \mathbf{F e}(\mathbf{n}, \mathbf{p})^{\mathbf{5 4}} \mathbf{M n}$ & 0.97 & 0.93 & 0.89 & 0.91 & 0.95 & 0.92 & 0.95 & 1.07 \\
\hline${ }^{\mathbf{5 8}} \mathbf{N i}(\mathbf{n}, \mathbf{p})^{\mathbf{5 8}} \mathbf{C o}$ & 0.98 & 0.91 & 0.88 & 0.91 & 0.95 & 0.93 & 0.91 & 1.02 \\
\hline \hline Average & 1.03 & 0.99 & 0.94 & 0.98 & 1.04 & 0.98 & 1.02 & 1.09 \\
\hline \% Standard Deviation & 6.3 & 9.2 & 7.5 & 7.9 & 10.3 & 6.3 & 10.3 & 7.0 \\
\hline
\end{tabular}

* Included 2nd Surveillance Test Results.

Table 2. Summary of Measurement to 2D-Calculation for Ex-Vessel of KSNP.

\begin{tabular}{|c|c|c|c|c|c|c|c|c|}
\hline Reaction & HB3 & HB4 & HB5 & HB6 & HU3 & HU4 & HU5 & HU6 \\
\hline${ }^{63} \mathbf{C u}(\mathbf{n}, \alpha)^{\mathbf{6 0}} \mathbf{C o}$ & 1.02 & 0.99 & 1.01 & 1.01 & 0.99 & 0.97 & 0.95 & 1.08 \\
\hline${ }^{46} \mathbf{T i}(\mathbf{n}, \mathbf{p})^{\mathbf{4 6}} \mathbf{S c}$ & 1.01 & 0.98 & 1.00 & 0.98 & 0.97 & 0.93 & 0.93 & 1.04 \\
\hline${ }^{54} \mathbf{F e}(\mathbf{n}, \mathbf{p})^{\mathbf{5} 4} \mathbf{M n}$ & 1.09 & 1.04 & 1.07 & 1.05 & 1.04 & 1.02 & 0.98 & 1.13 \\
\hline${ }^{\mathbf{5 8}} \mathbf{N i}(\mathbf{n}, \mathbf{p})^{\mathbf{5 8}} \mathbf{C o}$ & 1.03 & 0.96 & 1.01 & 0.99 & 0.98 & 0.94 & 0.91 & 1.05 \\
\hline${ }^{238} \mathbf{U}(\mathbf{n}, \mathbf{f})^{137} \mathbf{C s}$ & 1.14 & 0.98 & 1.16 & 1.11 & 1.08 & 1.07 & 0.97 & 1.15 \\
\hline${ }^{237} \mathbf{N p}(\mathbf{n}, \mathbf{f})^{137} \mathbf{C s}$ & 1.15 & 1.02 & 1.23 & 1.20 & 1.19 & 1.18 & 1.03 & 1.15 \\
\hline \hline Average & 1.07 & 1.00 & 1.08 & 1.06 & 1.04 & 1.02 & 0.96 & 1.10 \\
\hline \% Standard Deviation & 5.7 & 3.0 & 9.0 & 8.1 & 8.1 & 9.5 & 4.5 & 4.5 \\
Note: Ex-Vessel data included mid-plane capsule.
\end{tabular}

Table 3. Summary of Measurement to 3D-Calculation for In-Vessel of KSNP.

\begin{tabular}{|c|c|c|c|c|c|c|c|c|}
\hline Reaction & HB3 $^{*}$ & HB4* & HB5 & HB6 & HU3 & HU4 & HU5 & HU6 \\
\hline${ }^{\mathbf{6 3}} \mathbf{C u}(\mathbf{n}, \alpha)^{\mathbf{6 0}} \mathbf{C o}$ & 1.10 & 1.12 & 1.04 & 1.08 & 1.17 & 1.07 & 1.14 & - \\
\hline${ }^{46} \mathbf{T i}(\mathbf{n}, \mathbf{p})^{\mathbf{4 6}} \mathbf{S c}$ & 1.14 & 1.08 & 0.99 & 1.05 & 1.12 & 1.05 & 1.10 & 1.13 \\
\hline${ }^{54} \mathbf{F e}(\mathbf{n}, \mathbf{p})^{\mathbf{5 4}} \mathbf{M n}$ & 1.03 & 0.98 & 0.93 & 0.96 & 0.99 & 0.98 & 0.99 & 1.07 \\
\hline${ }^{\mathbf{5 8}} \mathbf{N i}(\mathbf{n}, \mathbf{p})^{\mathbf{5 8}} \mathbf{C o}$ & 1.04 & 0.97 & 0.93 & 0.96 & 0.99 & 1.00 & 0.95 & 1.01 \\
\hline \hline Average & 1.08 & 1.04 & 0.97 & 1.01 & 1.07 & 1.03 & 1.05 & 1.07 \\
\hline \% Standard Deviation & 4.8 & 7.1 & 5.5 & 6.1 & 8.6 & 4.1 & 8.6 & 5.6 \\
\hline
\end{tabular}

*Included 2nd Surveillance Test Results.

Table 4. Summary of Measurement to 3D-Calculation for Ex-Vessel of KSNP.

\begin{tabular}{|c|c|c|c|c|c|c|c|c|}
\hline Reaction & HB3 & HB4 & HB5 & HB6 & HU3 & HU4 & HU5 & HU6 \\
\hline${ }^{{ }^{3}} \mathbf{C u}(\mathbf{n}, \alpha)^{\mathbf{6 0}} \mathbf{C o}$ & 1.02 & 0.99 & 1.00 & 1.00 & 0.99 & 0.97 & 0.95 & 1.07 \\
\hline${ }^{46} \mathbf{T i}(\mathbf{n}, \mathbf{p})^{\mathbf{4 6}} \mathbf{S c}$ & 1.01 & 0.98 & 0.99 & 0.98 & 0.97 & 0.92 & 0.93 & 1.03 \\
\hline${ }^{\mathbf{5 4}} \mathbf{F e}(\mathbf{n}, \mathbf{p})^{\mathbf{5 4}} \mathbf{M n}$ & 1.08 & 1.03 & 1.06 & 1.04 & 1.03 & 1.00 & 0.97 & 1.10 \\
\hline${ }^{\mathbf{5 8}} \mathbf{N i}(\mathbf{n}, \mathbf{p})^{\mathbf{5 8}} \mathbf{C o}$ & 1.02 & 0.95 & 1.00 & 0.98 & 0.97 & 0.92 & 0.91 & 1.03 \\
\hline${ }^{238} \mathbf{U}(\mathbf{n}, \mathbf{f})^{137} \mathbf{C s}$ & 1.12 & 0.96 & 1.15 & 1.12 & 1.07 & 1.05 & 0.96 & 1.13 \\
\hline${ }^{237} \mathbf{N p}(\mathbf{n}, \mathbf{f})^{137} \mathbf{C s}$ & 1.14 & 1.01 & 1.22 & 1.19 & 1.19 & 1.17 & 1.02 & 1.14 \\
\hline \hline Average & 1.07 & 0.99 & 1.07 & 1.05 & 1.04 & 1.00 & 0.96 & 1.08 \\
\hline \% Standard Deviation & 5.3 & 3.1 & 8.9 & 8.3 & 8.2 & 9.3 & 4.2 & 4.5 \\
\hline
\end{tabular}

\section{3D Transport versus 2D/1D Synthesis Results Discussion}

Table 5 presents a summary of the comparison of the Adjusted Reference Temperature (ART) result between 2D/1D synthesis and RAPTOR-M3G.

According to Regulatory Guide 1.99 Revision 2[5], the adjusted reference temperature(ART) for each material in the beltline is given by the following expression:

$$
\mathrm{ART}=\text { Initial } \mathrm{RT}_{\mathrm{NDT}}+\Delta \mathrm{RT}_{\mathrm{NDT}}+\text { Margin }
$$




\section{$15^{\text {th }}$ ISRD}

Table 5. Comparison of ART Results between 2D/1D Synthesis and RAPTOR-M3G.

\begin{tabular}{|c|c|c|c|c|c|c|c|c|}
\hline ART $^{\circ}$ F (EOL) & HB3 & HB4 & HB5 & HB6 & HU3 & HU4 & HU5 & HU6 \\
\hline 2D/1D Synthesis & 74.2 & 54.5 & 11.2 & 41.0 & 83.2 & 33.2 & 24.2 & 32.6 \\
\hline 3D Transport & 73.2 & 53.9 & 10.6 & 40.6 & 82.6 & 32.4 & 23.7 & 32.0 \\
\hline
\end{tabular}

Initial $\mathrm{RT}_{\mathrm{NDT}}$ is the reference temperature for the unirradiated materials as defined in Paragraph NB2331 of Section III of the ASME Boiler and Pressure Vessel Code. $\Delta \mathrm{RT}_{\mathrm{NDT}}$ is the mean value of the adjustment in reference temperature caused by irradiation and should be calculated as follows:

$$
\Delta \mathrm{RT}_{\mathrm{NDT}}=(\mathrm{CF}) \mathrm{f}^{(0.28-0.10 \log \mathrm{f})}
$$

$\mathrm{CF}\left({ }^{\circ} \mathrm{F}\right)$ is the chemistry factor, a function of copper and nickel content. $\mathrm{CF}$ is given in Regulatory Guide 1.99 Revision 2 or the mean of the measured values. The neutron fluence at any depth in the vessel wall, $\mathrm{f}\left(10^{19} \mathrm{n} / \mathrm{cm} 2, \mathrm{E}>1 \mathrm{MeV}\right)$, is determined as follows:

$$
\mathrm{f}=\mathrm{f}_{\text {surf }}\left(\mathrm{e}^{-0.24 \mathrm{x}}\right)
$$

where $\mathrm{f}_{\text {surf }}\left(10^{19} \mathrm{n} / \mathrm{cm} 2, \mathrm{E}>1 \mathrm{MeV}\right)$ is the calculated value of the neutron fluence at the inner wetted surface of the vessel at the location of the postulated defect, and $\mathrm{x}$ (in inches) is the depth in the vessel wall measured from the vessel inner surface. The depth is $1 / 4 \mathrm{~T}$ and $3 / 4 \mathrm{~T}$ locations in the pressure vessel wall. Margin is the quantity, ${ }^{\circ} \mathrm{F}$, that is to be added to obtain conservative, upper-bound values of adjusted reference temperature for the calculations required by Appendix G to 10 CFR Part 50 .

ART of 2D/1D synthesis method show higher than RAPTOR-M3G at End of Life(32EFPY). The reason is that $2 \mathrm{D} / 1 \mathrm{D}$ synthesis method has excessive conservatism because of having just one model of R- $\theta$ and R-Z separately. RAPTOR-M3G performing 3D calculation can be applied to various reactor structures, because the code can simulate the model realistically and reasonably in geometric view points. The difference of ART Results between 2D/1D Synthesis and RAPTOR-M3G is less than 5\%, both method has a good assessment.

\section{References}

[1] The Code of Federal Regulations (CFRs), Title 10, Part 50, Appendix H, "Reactor Vessel Material Surveillance Program Requirements," US NRC

[2] US NRC Regulatory Guide 1.190, "Calculational and Dosimetry Methods for Determining Pressure Vessel Neutron Fluence"

[3] G. A. Fischer, "RadTrack: An Automated Tool for Tracking the Radiation Environment in LWRS, Version 1.1.” WCAP-16558-NP, Revision 1, Westinghouse Electric Company LLC (2008)

[4] S. L. Anderson, "Benchmark Testing of the FERRET Code for Least Squares Evaluation of Light Water Reactor Dosimetry," WCAP-16558-NP-A, Revision 0, Westinghouse Electric Company LLC (May 2006)

[5] Regulatory Guide 1.99, Revision 2, "Radiation Embrittlement of Reactor Vessel Materials," (May 1988)

[6] LTR-REA-14-28, Revision 0, "KRIST/Westinghouse Training Supplemental Information" Attachment 2, "Using Tecplot 360 to Visualize the Results of Transport Analysis" (February 2014) 